\title{
Cervical Mucinous Adenocarcinoma, Minimal Deviation Type
}

National Cancer Institute

\section{Source}

National Cancer Institute. Cervical Mucinous Adenocarcinoma, Minimal Deviation Type. NCI Thesaurus. Code C40206.

A rare, extremely well differentiated cervical mucinous adenocarcinoma in which most of the neoplastic glands cannot be disting uished from the normal endocervical glands. 